\title{
Statistical analysis of the second order effects variation with the stories height of reinforced concrete buildings
}

\section{Análise estatística da variação dos efeitos de segunda ordem com a altura dos pavimentos nos edifícios de concreto armado}

D. M. OLIVEIRA a

danielle@demc.ufmg.br

N. A. SILVA b

ney@dees.ufmg.br

C. C. RIBEIRO a

ccrstar@demc.ufmg.br

S. E. C. RIBEIRO a sidnea@ufmg.br

\begin{abstract}
In this paper the simplified method to evaluate final efforts using $\gamma_{z}$ coefficient is studied considering the variation of the second order effects with the height of the buildings. With this purpose, several reinforced concrete buildings of medium height are analyzed in first and second order using ANSYS software. Initially, it was checked that the $\gamma_{z}$ coefficient should be used as magnifier of first order moments to evaluate final second order moments. Therefore, the study is developed considering the relation (final second order moments/ first order moments), calculated for each story of the structures. This moments relation is called magnifier of first order moments, " $\gamma$ ", and, in the ideal situation, it must coincide with the $\gamma_{z}$ value. However, it is observed that the reason $\gamma / \gamma_{z}$ varies with the height of the buildings. Furthermore, using an statistical analysis, it was checked that $\gamma / \gamma_{z}$ relation is generally lower than 1,05 and varies significantly in accordance with the considered building and with the presence or not of symmetry in the structure.
\end{abstract}

Keywords: reinforced concrete, second order effects, $\gamma_{z}$ coefficient.

\section{Resumo}

Neste trabalho o processo simplificado de obtenção dos esforços finais utilizando o coeficiente $\gamma_{z}$ é estudado levando-se em conta a variação dos efeitos de segunda ordem ao longo da altura dos edifícios. Com este objetivo, diversos edifícios de médio porte em concreto armado são processados em primeira e segunda ordem utilizando o programa ANSYS. Inicialmente, mostra-se que o coeficiente $\gamma_{z}$ deve ser utilizado como majorador dos momentos de primeira ordem para a obtenção dos momentos finais. Assim, o estudo é conduzido considerando a relação entre os momentos obtidos pela análise em segunda e em primeira ordem, calculada para cada pavimento das estruturas. Esta relação entre os momentos é denominada de majorador dos momentos de primeira ordem, " $\gamma$ ", e, na situação ideal, deve coincidir com o valor de $\gamma_{z}$. Entretanto, observa-se que a razão $\gamma / \gamma$ varia ao longo da altura dos edifícios. Além disso, mostra-se, por meio de uma análise estatística, que a relação $\gamma / \gamma_{z}$ apresenta-se geralmente inferior a 1,05 e varia significativamente de acordo com o edifício considerado e a presença ou não de simetria na estrutura.

Palavras-chave: concreto armado, efeitos de segunda ordem, coeficiente $\gamma_{\mathrm{z}}$. 


\section{Introduction}

The intense process of verticalization of constructions and the technological evolution seen in the engineering field and in computational systems in the last years has enabled buildings to be slenderer. In these cases, the action of wind may produce significant effects, generating additional forces when simultaneously applied with other actions present in the structure. Therefore, the structure shall be designed taking into account the assessment of the global stability of the building. In reinforced concrete structures, this assessment can be made using the $\alpha$ instability parameter and $\gamma_{z}$ coefficient as provisioned by NBR 6118:2014 [1].

The $\alpha$ instability parameter is a horizontal displacement measure of the structure, assessing its sensibility to the second order effects. Above a certain limit of $\alpha$, the structure is then classified as sway structure, which then makes it necessary to take into consideration additional efforts that materialize in the deformed configuration.

Similarly to the $\alpha$ instability parameter, the $\gamma_{z}$ coefficient can be used to classify structures (non-sway or sway structures). However, the $\gamma_{z}$ coefficient goes beyond the $\alpha$ instability parameter as it can also be used to assess final efforts that include second order efforts, provided that its value is not over a certain limit.

Even though, as the $\gamma_{z}$ coefficient presents a single value for the entire structure, using it may result in underestimated final efforts for some stories, and overestimated for others. This is because the second order effects undergo variations along the height of the building, as stated in several studies (Carmo [2], Lima \& Guarda [3] and Oliveira [4]).

Within such context, this study intends to assess the simplified process of calculating final efforts using the $\gamma_{z}$ coefficient considering the variation of second order effects along the height of the building. With that objective in mind, a statistical analysis will be made on the results obtained by Oliveira et al. [5], who analyzed in first and second orders several different medium-sized reinforced concrete buildings using software ANSYS [6].

\section{Second order effects and classification of structures}

NBR 6118:2014 [1] distinguishes the following second order effects as follows:

- global effects: second order effects introduced by horizontal displacements of structural joints, when subject to vertical and horizontal loads;

local effects: happening in structural bars when the respective axis are no longer straight;

- localized effects: happening in wall-like columns, in regions with non-linearity greater than that of the column axis as a whole.

Also accordingly with NBR 6118:2014 [1], the structure should be classified as a non-sway structure when global second order effects are less than $10 \%$ of the respective first order efforts, which may then be neglected. Otherwise (global second order effects greater than $10 \%$ of first order effects) it is classified as a sway structure. It is worth noting that the non-consideration of second order global effects does not imply in non-consideration of local and localized effects, since global stability does not guarantee local stability and vice-versa. Therefore, both in non-sway structures and in sway structures, it is compulsory to take into consideration both local and localized second order effects. In this study, as it is related exclusively to second order global effects, they will be referred to only as second order effects.

Therefore, considering the bending moments, for example, a structure will be classified as a non-sway structure if:

$$
M_{2 d} \leq 1.1 M_{1 d}
$$

where as:

- $M_{2 d}$ is total design moment that includes second order effects;

- $M_{1 d}$ is the first order design moment.

However, this is not the verification that is put into practice, since it would be necessary to realize a second order analysis, which is often only desirable to sway structures.

Thus, it is indeed useful to find processes that enable the classification of structures with only the first order analysis results. So, when a structure is classified as sway structure, the designer will be able to choose between making it stiff and classifying it as a non-sway structure, or making a second order analysis.

Different parameters have been proposed, some determined from critical loads, others in function of the stiffness of stories. Among these, of note is the $Y_{z}$ coefficient, presented by Franco \& Vasconcelos [7].

\section{3. $\gamma_{z}$ Coefficient}

When making a linear analysis of horizontal and vertical actions, the first order moment $M_{1}$ can be calculated in relation to the structure basis, as well as the horizontal displacements of the structure joints. These displacements, in combination with vertical forces, lead to an increased number of $\Delta \mathrm{M}_{2}$ moments, thus causing new displacements. This process occurs successively along several different stages, or iterations, generating an increased number of shorter moments. If the structure is stable, these increases will decrease until they become practically negligible. With the several increases in moments, the final moment $M_{2}$ is then determined, thus including the second order moment:

$$
M_{2}=M_{1}+\Delta M_{2}+\Delta M_{3}+\ldots+\Delta M_{j}
$$

$j$ means the number of iterations.

When admitting that the moments $M_{1}, \Delta M_{2}, \Delta M_{3}, \ldots, \Delta \mathrm{M}_{j}$ constitute a geometric progression, the ratio is given by:

$r=\frac{\Delta M_{2}}{M_{1}}=\frac{\Delta M_{3}}{\Delta M_{2}}=\ldots=\frac{\Delta M_{j}}{\Delta M_{j-1}}<1$

and it can be written:

$$
M_{2}=\left(1+r+r^{2}+r^{3}+\ldots+r^{j-1}\right) M_{1}
$$


When $j$ is tended to infinity, the equation (4) is like:

$$
M_{2}=\frac{1}{1-r} \cdot M_{1} \quad \text { or } \quad M_{2}=\frac{1}{1-\frac{\Delta M_{2}}{M_{1}}} \cdot M_{1}
$$

Naming $\gamma_{z}$ as the factor that magnifies the first order moment and using design values, one obtains:

$$
\gamma_{z}=\frac{1}{1-\frac{\Delta M_{d}}{M_{1 d}}}
$$

The $\gamma_{z}$ coefficient can, then, be calculated from a linear analysis, determining the first order moment $M_{1 d}$ and the moments increase $\Delta \mathrm{M}_{d^{*}}$ NBR 6118:2014 [1] states that a linear analysis of first order must be realized by reducing the stiffness of structural elements (to consider the physical non-linearity in approximation) and that the $Y_{z}$ coefficient is valid for reticulated structures of at least 4 stories. According to França [8] apud Bueno [9], this limitation of the number of stories is related to the lack of studies on the nonlinearity approximation for low reticulated structures since this directly influences the values of displacements that will generate additional effects to the structure. The more these values are closer to real displacements, the better the prediction of effort amplification will be.

According to NBR 6118:2014 [1], for each combination of loads, the $\gamma_{z}$ value can be obtained with the equation:

$$
\gamma_{z}=\frac{1}{1-\frac{\Delta M_{t o t, d}}{M_{1, t o t, d}}}
$$

Where as:

- $M_{1, \text { tot,d }}$ : moment of tipping, that is, the sum of the moment of all horizontal forces, with design values, in relation to the base of the structure.

- $\Delta \mathrm{M}_{\text {tot, } d}$ : is the sum of the products of all the vertical forces acting on the structure, with design values, by the horizontal displacements of their respective points of application.

Remembering that the second order effects can be neglected provided that they do not represent an increase greater than $10 \%$ of the respective first order effects, a structure may be classified as non-sway if its $\gamma_{z} \leq 1.1$.

It is important to note that, obviously, the lesser the value of the $\gamma_{z}$ coefficient, the more stiff the structure is, which is easily verified with the analysis of the equation [7]. If the horizontal displacements of the structure are in fact large, so that the increase in moments $\Delta \mathrm{M}_{\text {tot,d }}$ becomes approximately equal to moment $M_{1, \text { tot, } d^{\prime}}$, that is, $\Delta \mathrm{M}_{\text {tot, }, d} / M_{1, t o t, d} \cong 1$, the $\mathrm{Y}_{z}$ coefficient is tended to infinity. This would be the case of an infinitely flexible structure. On the other hand, for an infinitely stiff structure, that is, one that does not displace under loads action, $\Delta \mathrm{M}_{\text {tot, } d}$ would be null and, consequently, the $\gamma_{z}$ coefficient would be equal to 1 .
Lacerda et al. [10] conducted a study on global stability determining the $\alpha$ parameter of instability and the $\gamma_{z}$ coefficient for a reinforced concrete building, analyzing it with and without its rigid core in the central area. Based on the assessments made, the authors found that the utilization of rigid cores significantly influences the global stability of the structures, mainly in tall buildings. Additionally, as the rigid core enables a reduction in cross sections of the other structural elements that constitute the building, it could also be used in buildings that are not so slender.

Freitas [11], in his study about the assessment of global stability of buildings with and without bracing elements, adds that in addition to rigid core, other solutions also contribute to structural stiffness, such as frames formed by beams and columns, and a concrete wall system.

Freitas et al. [12] calculated the values of $\alpha$ and $\gamma_{z}$ by simulating a building with the structural modeling software CAD/TQS. Two structural solutions were adopted: one without wall-like columns and another one with wall-like columns. The $\gamma_{z}$ values obtained from models without wall-like columns were greater than from those with wall-like columns. Additionally, the variation of stresses on the columns of models with wall-like columns produced a small difference between the $\gamma_{z}$ results obtained. For the models without wall-like columns, the variation of stresses on the columns significantly altered $\gamma_{z}$ values. Eventually, the authors concluded that the variation of the stress on columns is not a decisive factor to obtain acceptable $\gamma_{z}$ values but, instead, it is the presence of elements that collaborate with bending stiffness. In this study, the authors opted to use wall-like columns. However, alternatives can also be used, like high stiffness beams, reinforced concrete structural walls, increase of the columns sections in the direction of less rigidity of the structure.

Passos et al. [13] studied the global stability of slender buildings composed by flat slabs, with slenderness approximately one to six, modeling the building with non-adherent prestressed and waffle slabs. Among factors that enable reductions in the $\gamma_{z}$ coefficient are: the increase of thickness in prestressed slabs, and the increase of the waffle slabs cover, the reduction of ceiling height between stories in the models and the application of a greater value of the coefficient that considers physical non-linearity in the prestressed slabs. Similar conclusions were found by Feitosa \& Alves [14], as they noted that the increase of the thickness of prestressed slabs contributes significantly to the building's global stability. When the building is not built with beams, the consideration of the slabs as a resistant element to horizontal efforts becomes even more relevant.

It is worth noting that the $\gamma_{z}$ coefficient is not used only to assess global stability of the structure, rating it as non-sway or sway. The $\gamma_{z}$ also can be employed to estimate final efforts, which include second order efforts, provided that its value is not beyond a certain limit. According to NBR 6118:2014 [1], final efforts that include second order effects can be assessed based on additional increases of horizontal forces from the load combination considered as $0.95 \gamma_{z}$, provided that $\gamma_{z}$ is not higher than 1.3. However, according to NBR 6118:2000 [15] Review Project, final effort values could be obtained by multiplying the first order moments by $0.95 \gamma_{z}$, also under the condition that $\gamma_{z} \leq 1,3$. It can then be noted once considered an increasing factor of first order moments, $\gamma_{z}$ became the increasing coefficient of horizontal actions. 
According to Moncayo [16], when applying $\gamma_{z}$ as an effort magnifier to obtain second order efforts generates much better results than when applying $0.95 \gamma_{z}$.

Franco \& Vasconcelos [7] understand that a good estimate of second order results analysis can be obtained when using $\gamma_{z}$ as the magnifier of first order moments.

In this study an efficiency analysis of the $\gamma_{z}$ coefficient will be initially made considering it a magnifier of first order efforts (not only of bending moments, but also of axial and shear forces) and also a magnifier of horizontal actions, with the goal to obtain final efforts, which include second order efforts. Next, the increasing process considered the most efficient will be studied taking in consideration the variation of second order effects along the building height based on a statistical analysis of the results obtained.

\section{Measurements and statistical tests}

Data collection represents only the initial stage of a statistical analysis that will transform them into a significant set of measurements, thus validating the scientific research.

Several measurements may be used to describe a set of data, among them: mean and median (central tendency measures); standard deviation, coefficient of variation, minimum and maximum (variability measures).

Graphic presentations such as boxplot charts and histograms are useful to increase data legibility. Histograms are used to showcase continuous measures, mainly in terms of intervals. Boxplots show simultaneously a series of aspects regarding distribution, as mean, median, minimum and maximum.

It important to note that, according to Levin et al. [17], the descriptive approach does not constitute the main goal in decision making and most researchers are attentive to hypothesis tests, which are in general related to the differences between groups.

Kruskal-Wallis tests may be used to compare three or more groups. So, two hypotheses must be initially defined, null and alternative hypotheses. The null hypothesis $\left(H_{0}\right)$ establishes that several groups do not significantly differ, whereas, accordingly with the alternative hypothesis $\left(H_{1}\right)$, there are significant differences between some or all groups.

The Kruskal-Wallis test involves the determination of a statistics, $H$, that has to be compared with a table critical value. Based on this comparison, one may decide between rejecting the null hypothesis or not.

Statistics $H$ can be calculated as follows:

$$
H=\frac{12}{N(N+1)} \sum_{i=1}^{a} \frac{R_{i T}^{2}}{n_{i}}-3(N+1)
$$

where:

- $N$ is the total number of observations;

- $a$ is the number of samples;

- $n_{i}$ represents the number of observations from sample $i$;

- $R_{i T}$ is the total of the sample posts $i$. For calculating $R_{i T,}$ all $N$ observations must be ordered from smaller to largest, and the smaller will be attributed post 1 , the next one post 2 , and so on, until the largest observation is attributed post $N$. Finally, the $R_{i T}$ value is then obtained by summing the posts related to sample $i$.

The null hypothesis shall be rejected if:

$$
H \geq \chi_{\alpha, a-1}^{2}
$$

whereas $\chi_{\alpha, a-1}^{2}$ is the critical table value (it can be found, for instance, in Werkema \& Aguiar [18]), correspondingly to a certain a significance level and with a-1 degrees of freedom. The a significance level represents a probability to reject the null hypothesis when it is true. Therefore, the smaller the a value is, the larger will be the confidence in the decision to reject $H_{0}$. Conventionally $\alpha=$ 0.05 is adopted, which means that there is a probability that $H_{0}$ equal to $5 \%$ will be rejected when it is true. It is worth noting that, in several different situations, it may be convenient to make a test of hypothesis by means of a comparison between the a significance level and the $p$ value, which indicates the weight of the evidence as opposed to $H_{0}$. If $p$ is small, there is a strong evidence to reject the null hypothesis. In general, it can be written:

$-p<\alpha \Rightarrow H_{0}$ is rejected;

$-p \geq \alpha \Rightarrow H_{0}$ is not rejected.

The $p$ value can be obtained through tables or, in more complex cases, utilizing statistical programs. More details regarding how to obtain $p$ values can be found in Montgomery \& Runger [19].

In order to compare pairs of groups, one can use the Mann-Whitney test. This test, similarly to the Kruskall-Wallis test, is based on the definition of two hypotheses and in the comparison of a statistics calculated with a critical table value. So, the null hypothesis $\left(H_{0}\right)$ establishes that there are no significant differences between the two groups, whereas, according to alternative hypothesis $\left(H_{1}\right)$, the groups differ significantly.

In the case of samples with sizes greater than eight, the null hypothesis will be rejected if:

$$
\left|z_{0}\right|>z_{\alpha / 2}
$$

where, $z_{0}$ is the statistics to be compared with the critical table value $z_{\alpha / 2}$, found in Werkema et al. [20] and Montgomery \& Runger [19], among others.

$z_{0}$ can be calculated using the following:

$$
z_{0}=\frac{w_{1}-\mu_{w 1}}{\sigma_{w 1}}
$$

where:

- $w_{1}$ the sum of the posts in the smaller sample;

- $\mu_{w 1}$ is the distribution mean of $w_{1}$, calculated with:

$$
\mu_{w 1}=\frac{n_{1}\left(n_{1}+n_{2}+1\right)}{2}
$$

where $n_{1}$ and $n_{2}$ are the number of observations from the smaller and the largest samples, respectively; 
- $\sigma_{w 1}$ is the standard deviation of $w_{1}$ distribution, defined like:

$\sigma_{w 1}=\sqrt{\frac{n_{1} n_{2}\left(n_{1}+n_{2}+1\right)}{12}}$

\section{Numerical applications}

In order to conduct the study, the results obtained by Oliveira et al. [5] will be analyzed and complemented. The above mentioned authors processed in first and second order using software ANSYS [6], ten medium-sized reinforced concrete buildings, whose main characteristics are depicted in table [1]. Tridimensional models were used, representing columns and beams by means of bar element "beam 4", which shows six degrees of freedom at each node: three translations and three rotations, in directions $X, Y$ e $Z$.

As described by Oliveira et al. [5], the buildings were processed considering both vertical actions (composed by permanent loads and accidental loads) and horizontal actions (corresponding to the action of wind, in directions parallel to axes $X$ and $Y$ ). The coefficients applied to the actions were determined based on the ultimate normal combination that considers the wind as a main variable action, being determined according to NBR 6118:2014 [1].

The processing of structures in second order was made by means of a non-linear geometric analysis considering the physical nonlinearity in a simplified manner through the reduction of stiffness of structural elements (values equal to $0.8 I_{c}$ were adopted for columns and $0.4 I_{c}$ for beams, whereas $I_{c}$ is the inertia moment of the gross concrete section).

\subsection{Values obtained for the $\gamma_{z}$ coefficient}

Initially, with the results from the first order analysis, $\gamma_{z}$ coefficients were calculated for all buildings in directions $X$ and $Y$. Table [2] shows the values obtained, along with the classification of structures, in both directions.

\subsection{Assessment of $\gamma_{z}$ as magnifier of first order efforts (bending moments, axial and shear forces) to calculate final efforts}

For all stories of buildings, the relation between the efforts obtained through second and first order analyses in directions $X$ and $Y$ were calculated based on processing structures in first and second orders for the vertical actions acting simultaneously with horizontal actions. Only really relevant efforts were taken into account in structural dimensioning: bending moments and axial forces for columns; bending moments and shear moments for beams.

Table [3] presents the average results for stories and $\gamma_{z}$ values for all buildings in both directions. Therefore, when making a comparative analysis between the increases undergone by first order efforts, considering second order effects and the increases predicted by the $\gamma_{z}$ coefficient, it can be noted that:

- for the axial force in columns and the shear force in beams, the average increases are very small (between $1 \%$ and $4 \%$ ), lower than those predicted by $\gamma_{z}$. Therefore, increasing these forces with the $\gamma_{z}$ coefficient is not necessary, even for high $\gamma_{z}$ values (such as, for example, in the case of building II in direction $X$ );

the average increases obtained in the bending moment of columns and beams present good proximity in relation to $\gamma_{z}$. For the bending moment of columns, the greater difference between the average increases and those predicted by $\gamma_{z}$ correspond to $6 \%$ (building III, direction $Y$ ), in favor of safety. As to the bending moment of beam, the maximum difference, corresponding to the increase obtained for building I in direction $X$, is around $6.7 \%$, also in favor of safety. Considering exclusively those cases in which increases by $\gamma_{z}$ would be against safety, maximum differences can be noted below $5 \%$ for the moment in columns (building III, direction $X$ ), and below $4 \%$ for the moment in beams (building II, direction $Y$ ).

\section{Table 1}

\section{Main characteristics of analyzed buildings}

\begin{tabular}{|c|c|c|c|c|c|c|}
\hline Building & $\mathrm{N}^{\circ}$ of stories & $\begin{array}{c}\text { Ceiling height } \\
(\mathrm{m})\end{array}$ & $\mathrm{N}^{\circ}$ of slabs & $\mathrm{N}^{\circ}$ of beams & $\mathrm{N}^{\circ}$ of columns & $\mathrm{f}_{\mathrm{ck}}(\mathrm{MPa})$ \\
\hline I & 16 & 2.90 & 8 & 8 & 15 & 20 \\
\hline II & 18 & 2.55 & 11 & 21 & 16 & 30 \\
\hline III & 20 & 2.75 & 9 & 10 & 15 & 45 \\
\hline IV & 30 & 2.85 & 4 & 6 & 9 & 20 \\
\hline V & 22 & 2.75 & 11 & 20 & 22 & 65 \\
\hline VI & 15 & 2.90 & 9 & 8 & 16 & 25 \\
\hline VII & 18 & 2.88 & 10 & 11 & 16 & 25 \\
\hline VIII & 18 & 2.70 & 17 & 31 & 28 & 25 \\
\hline IX & 20 & 2.56 & 12 & 27 & 14 & 30 \\
\hline X & 20 & 2.90 & 6 & 9 & 12 & 25 \\
\hline
\end{tabular}


Table 2

Values of $\gamma_{z}$ coefficients and classification of structures

\begin{tabular}{|c|c|c|c|}
\hline Building & Direction & $\gamma_{z}$ & Classification \\
\hline \multirow{2}{*}{ I } & $\mathrm{X}$ & 1.19 & Sway structure \\
\cline { 2 - 4 } & $\mathrm{Y}$ & 1.14 & Sway structure \\
\hline \multirow{3}{*}{ II } & $\mathrm{X}$ & 1.32 & Sway structure \\
\cline { 2 - 4 } & $\mathrm{Y}$ & 1.16 & Sway structure \\
\hline \multirow{3}{*}{ III } & $\mathrm{X}$ & 1.06 & Non-sway structure \\
\hline \multirow{2}{*}{ V } & $\mathrm{Y}$ & 1.32 & Sway structure \\
\hline \multirow{2}{*}{ VI } & $\mathrm{X}$ & 1.30 & Sway structure \\
\hline \multirow{2}{*}{ VII } & $\mathrm{Y}$ & 1.17 & Sway structure \\
\hline \multirow{2}{*}{ VIII } & $\mathrm{X}=\mathrm{Y}$ & 1.28 & Sway structure \\
\cline { 2 - 4 } & $\mathrm{X}$ & 1.21 & Sway structure \\
\hline \multirow{2}{*}{ IX } & $\mathrm{Y}$ & 1.27 & Sway structure \\
\hline & $\mathrm{X}$ & 1.14 & Sway structure \\
\hline \multirow{2}{*}{$\mathrm{X}$} & $\mathrm{Y}$ & 1.30 & Sway structure \\
\hline & $\mathrm{X}$ & 1.22 & Sway structure \\
\hline & $\mathrm{Y}$ & 1.31 & Sway structure \\
\hline & $\mathrm{X}$ & 1.29 & Sway structure \\
\hline & $\mathrm{Y}$ & 1.30 & Sway structure \\
\hline
\end{tabular}

The chart in figure [1] lists $\gamma_{z}$ coefficients correspondingly to all buildings in both directions with average values of the relation (second order moment/first order moment), for columns and beams,

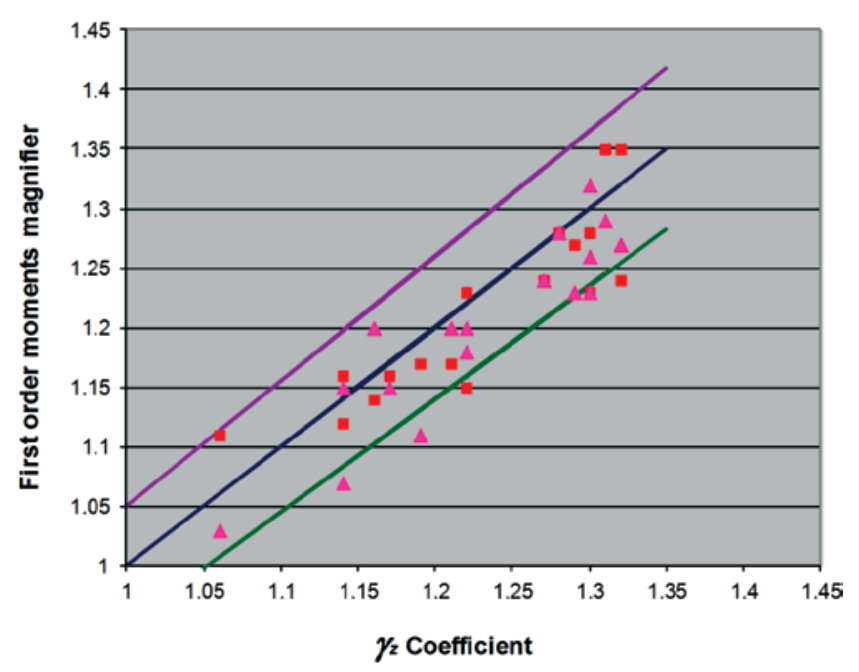

- Magnifiers obtained for columns moment

$\Delta$ Magnifiers obtained for beams moment

- Ideal line: magnifiers equal to $\gamma_{z}$

— Line with magnifiers $5 \%$ lower than $\gamma_{z}$

- Line with magnifiers $5 \%$ greater than $\gamma_{2}$

Figure 1

Relation between magnifiers of first order moments and $\gamma_{z}$ coefficients respectively. In this chart first order moments magnifier is the name given to the relation between the moments since it represents the values the first order moments should be multiplied by to obtain the final moments, which include the second order effects. Therefore, a specific magnifier is corresponding to each $\gamma_{z}$ coefficient, as indicated in table [3] ( $3^{\text {rd }}, 5^{\text {th }}$, and $7^{\text {th }}$ columns). The closer they are to $\gamma_{z}$ values and to the obtained magnifier, the greater $\gamma_{z}$ efficiency is as first order moments magnifier to determine final moments.

It can be seen in figure [1] that, as previously noted, in both cases of columns and of beams, first order moments magnifiers differences are not very significant (that is, they are always below 5\%) when compared to $\gamma_{z}$. That can be promptly noted in the proximity of the points in relation to the line called "ideal", which corresponds to values equal to the magnifier obtained and the $\gamma_{z}$ coefficient. Additionally, it can be observed that the majority of points is found below the "ideal" line, which means that the magnifier obtained is lower than $\gamma_{z}$, and, consequently, in these cases magnifying the first order moments by $\gamma_{z}$ would favor safety. It is worth noting that this magnifying proved to be against safety in only $28 \%$ of the cases for the moment in columns and $17 \%$ of the cases for the moment in beams, as can be verified by the small number of points above the "ideal" line.

Therefore, initially, obtaining final moments (first order + second order) based on magnifying first order moments by $\gamma_{z}$ can be seen as satisfactory. However, it is important to note that this study was conducted in structures that feature maximum $\gamma_{z}$ values around 1.3 , that is, for these the simplified process of evaluation of final efforts utilizing $\gamma_{z}$ coefficient is still valid, according to NBR 6118:2014 [1]. Moreover, average increases of structures as a whole were considered, not taking into account the variation of second order effects with the building story height. This variation will be detailed in item 5.4 . 


\subsection{Assessment of $\gamma_{z}$ as magnifier of horizontal actions to obtain final efforts}

With the goal to assess the performance of $\gamma_{z}$ as a horizontal action magnifier to obtain final efforts, the buildings were analyzed in first and second orders, regarding vertical actions acting simultaneously with horizontal actions. However, the processing of structures in first order was made with horizontal actions that were additionally magnified by $0.95 \gamma_{z}$. It was then calculated the relation between the efforts obtained by the analysis in second order and in first order, for all building stories in both directions. The average values of stories are shown in table [4].

It is important to mention that the effort values obtained in the first order analysis should, in this case, represent the final values of the efforts (first order + second order), since they were determined with horizontal actions additionally magnified by $0.95 \gamma_{z}$. Therefore, the relation between efforts obtained through the analysis in second and first order should be equal to 1.0 , that is, at least close to this value. In fact, this occurs both for axial force in columns and for shear force in beams, as can be observed in table [4]. However, such relations already presented values close to 1.0 even when the first order analysis was made without additionally magnifying horizontal actions by $0.95 \gamma_{z}$, which can be seen in table [3]. Therefore, it can be said that for the axial force in columns and for shear force in beams, the first order analyses made with or without additionally magnifying the horizontal actions by $0.95 \gamma_{z}$ provide practically the same results. Also in table [4], it can be seen that for bending moments in columns and beams the average relations between results in second and first orders present, in general, values that are distant from
1.0 , reaching pretty significant values, such as, in the case of building IX, direction $X$ (equal to 1.25 and 1.28 for columns and beams, respectively). It is worth observing that the differences between moments obtained in second and first order analyses go above $10 \%$ in $94 \%$ of the cases for columns, and in $83 \%$ for beams. Consequently, obtaining final moments based on additionally magnifying horizontal actions by $0.95 \gamma_{z}$ does not comply with good results. Finally, it can be observed that, for the buildings analyzed in this study, the simplified process of final efforts assessment that uses coefficient as a first order moments magnifier (and not as a horizontal actions magnifier), provides results that are close to those obtained in second order analyses. It is important to note that, as said in item 5.2 , it is not necessary to magnify axial force in columns and shear force in beams by $\gamma_{z}$ coefficient, since for these efforts the first and second order values obtained are practically the same.

\subsection{Studying second order effects variations in relation to building story heights}

In this item, the simplified final efforts assessment method using $\gamma_{z}$ coefficient is studied taking into consideration the variation of second order effects along the buildings' heights. This study considers the magnifying process that provided results closer to those obtained with a second order analysis, according to items 5.2 and 5.3. Consequently, the $\gamma_{z}$ coefficient is considered a first order moments magnifier for determining final moments, based on the principle that axial force in columns and shear force in beams are obtained directly with the first order analysis.

The study under analysis is made comparing, for each story of the

\section{Table 3}

$\gamma_{z}$ coefficients and average values of ratio (second order effort / first order effort)

\begin{tabular}{|c|c|c|c|c|c|c|}
\hline \multirow[b]{2}{*}{ Building } & \multirow[b]{2}{*}{ Direction } & \multirow[b]{2}{*}{$\gamma_{z}$} & \multicolumn{2}{|c|}{ Columns } & \multicolumn{2}{|c|}{ Beams } \\
\hline & & & Axial force & $\begin{array}{l}\text { Bending } \\
\text { moment }\end{array}$ & Shear force & $\begin{array}{l}\text { Bending } \\
\text { moment }\end{array}$ \\
\hline \multirow[t]{2}{*}{ I } & $x$ & 1.19 & 1.01 & 1.17 & 1.01 & 1.11 \\
\hline & $\mathbf{Y}$ & 1.14 & 1.01 & 1.16 & 1.01 & 1.07 \\
\hline \multirow{2}{*}{ II } & $x$ & 1.32 & 1.01 & 1.35 & 1.02 & 1.27 \\
\hline & $Y$ & 1.16 & 1.02 & 1.14 & 1.03 & 1.20 \\
\hline \multirow{2}{*}{ III } & $x$ & 1.06 & 1.02 & 1.11 & 1.03 & 1.03 \\
\hline & $\mathbf{Y}$ & 1.32 & 1.02 & 1.24 & 1.04 & 1.27 \\
\hline IV & $X=Y$ & 1.30 & 1.03 & 1.23 & 1.03 & 1.23 \\
\hline \multirow{2}{*}{ V } & $x$ & 1.17 & 1.02 & 1.16 & 1.03 & 1.15 \\
\hline & $Y$ & 1.28 & 1.03 & 1.28 & 1.01 & 1.28 \\
\hline VI & $X=Y$ & 1.21 & 1.02 & 1.17 & 1.03 & 1.20 \\
\hline \multirow{2}{*}{ VII } & $x$ & 1.27 & 1.02 & 1.24 & 1.04 & 1.24 \\
\hline & $Y$ & 1.14 & 1.03 & 1.12 & 1.04 & 1.15 \\
\hline \multirow{2}{*}{ VIII } & $\mathrm{X}$ & 1.30 & 1.02 & 1.28 & 1.03 & 1.32 \\
\hline & $\mathbf{Y}$ & 1.22 & 1.02 & 1.23 & 1.03 & 1.20 \\
\hline \multirow{2}{*}{ IX } & $X$ & 1.31 & 1.01 & 1.35 & 1.02 & 1.29 \\
\hline & $Y$ & 1.29 & 1.01 & 1.27 & 1.02 & 1.23 \\
\hline \multirow{2}{*}{$x$} & $x$ & 1.30 & 1.02 & 1.28 & 1.03 & 1.26 \\
\hline & $\mathbf{Y}$ & 1.22 & 1.02 & 1.15 & 1.03 & 1.18 \\
\hline
\end{tabular}




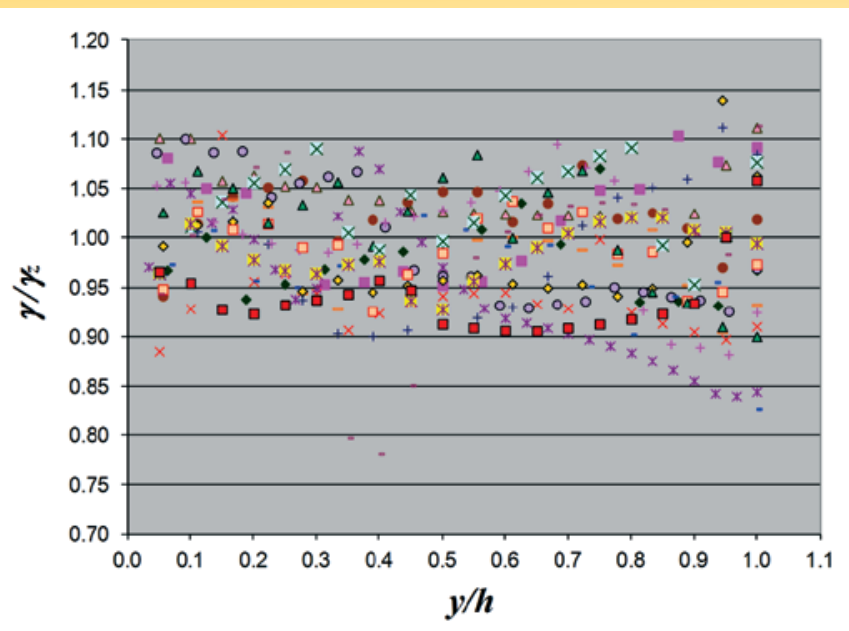

\footnotetext{
- Building I - Direction X $X$ Building I - Direction $Y$ + Building II - Direction $Y \quad \Delta$ Building III - Direction X

× Building IV - Direction $X=Y$ o Building V - Direction $X$ - Building VI - Direction $X=Y$ - Building VII - Direction $X$ 口Building VIII - Direction X $\triangle$ Building VIII - Direction $Y$ * Building IX - Direction $Y$ - Building $X$ - Direction $X$

\section{Figure 2}

Variation of the $\gamma / \gamma_{z}$ ratio along the building height in both directions for columns
}

- Building II - Direction X

$\times$ Building III - Direction $Y$

+ Building V - Direction Y

- Building VII - Direction Y

$\times$ Building IX - Direction $X$

a Building $X$ - Direction $Y$ structure, the increases experienced by the first order moments, when considering the second order effects, and those increases predicted by the $\gamma_{z}$ coefficient. So, the relation between the moments obtained with second order and first order analyses (for columns and beams, respectively), along all buildings' heights for directions $X$ and $Y$, is considered. This relation between moments can be denominated first order moments magnifier, " $\gamma$ ", since, as commented in item 5.2, it represents the value by which the first order moments are to be multiplied to obtain final moments, which include second order effects. In the ideal situation, in which magnifying first order moments by $\gamma_{z}$ provides final moments with a precision of $100 \%, \gamma$ and $\gamma_{z}$ values must coincide as to every story in the buildings, that is, $\gamma / \gamma_{z}=1$ all along the height.

Based on the considerations presented, figures [2] and [3] charts were made and represent the variation of the $\gamma / \gamma_{z}$ ratio along the height of all buildings, in both directions, for columns and beams, respectively. In these charts, the axis of abscissas corresponds to the relation $y / h$, where $y$ represents the story height and $h$ the total height of the structure.

Figures [2] and [3] show that most of $\gamma / \gamma_{z}$ values seem to be, approximately, between 0.90 and 1.10 , for both columns and beams. It can also be noted that it is not possible to precisely assess the variation and distribution of $\gamma / \gamma_{z}$ by simply observing figures [2] and [3]. Consequently, for a better assessment of the obtained results, a statistical analysis will be made using software MINITAB [21].

\subsubsection{Statistical analysis}

Initially, the central tendency measures (mean and median) and variability measures (standard deviation, coefficient of variation,

\section{Table 4}

Average values of ratio (second order effort / first order effort obtained with horizontal actions additional magnified by $0.95 \gamma_{z}$ )

\begin{tabular}{|c|c|c|c|c|c|}
\hline \multirow[b]{2}{*}{ Building } & \multirow[b]{2}{*}{ Direction } & \multicolumn{2}{|c|}{ Columns } & \multicolumn{2}{|c|}{ Beams } \\
\hline & & Axial force & Bending moment & Shear force & $\begin{array}{l}\text { Bending } \\
\text { moment }\end{array}$ \\
\hline \multirow[t]{2}{*}{ I } & $x$ & 1.01 & 1.15 & 1.01 & 1.08 \\
\hline & $Y$ & 1.01 & 1.14 & 1.02 & 1.05 \\
\hline \multirow{2}{*}{ II } & $x$ & 1.01 & 1.22 & 1.02 & 1.29 \\
\hline & $Y$ & 1.02 & 1.12 & 1.03 & 1.20 \\
\hline \multirow{2}{*}{ III } & $x$ & 1.02 & 1.11 & 1.02 & 1.03 \\
\hline & $Y$ & 1.02 & 1.18 & 1.03 & 1.24 \\
\hline IV & $X=Y$ & 1.03 & 1.15 & 1.03 & 1.18 \\
\hline \multirow{2}{*}{ v } & $x$ & 1.02 & 1.14 & 1.03 & 1.14 \\
\hline & $Y$ & 1.03 & 1.17 & 1.00 & 1.19 \\
\hline VI & $X=Y$ & 1.02 & 1.09 & 1.03 & 1.14 \\
\hline \multirow{2}{*}{ VII } & $x$ & 1.02 & 1.14 & 1.04 & 1.20 \\
\hline & $Y$ & 1.03 & 1.11 & 1.04 & 1.13 \\
\hline \multirow{2}{*}{ VIII } & $x$ & 1.02 & 1.17 & 1.03 & 1.33 \\
\hline & $Y$ & 1.02 & 1.16 & 1.02 & 1.17 \\
\hline \multirow{2}{*}{ IX } & $x$ & 1.01 & 1.25 & 1.02 & 1.28 \\
\hline & $Y$ & 1.01 & 1.19 & 1.03 & 1.20 \\
\hline \multirow{2}{*}{$\mathrm{x}$} & $x$ & 1.02 & 1.16 & 1.01 & 1.22 \\
\hline & $\mathbf{Y}$ & 1.02 & 1.11 & 1.03 & 1.16 \\
\hline
\end{tabular}




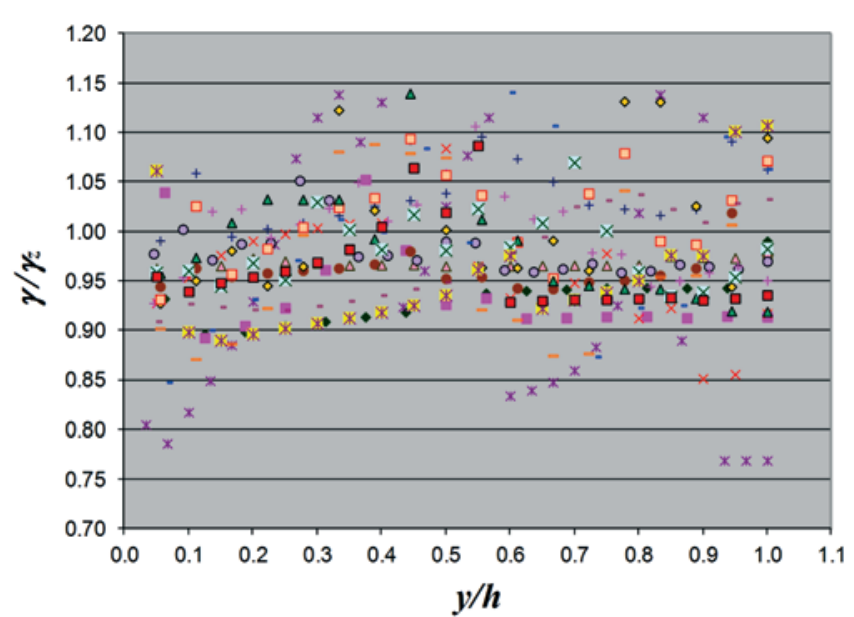

- Building | - Direction X =Building | - Diretion $Y$

+ Building II - Direction $Y \quad \triangle$ Building III - Direction $X$

$\times$ Building IV - Direction $X=Y$ คBuilding V - Direction $X$

- Building VI - Direction $X=Y$ - Building VII - Direction $X$

$\square$ Building VIII - Direction $X \quad \Delta$ Building VIII - Direction $Y$

* Building IX - Direction $Y$ - Building $X$ - Direction $X$

- Building II - Direction X

$\times$ Building III - Direction $Y$

+ Building V - Direction $Y$

$\diamond$ Building VII - Direction Y

$\times$ Building $I X-$ Direction $X$

a Building $X$ - Direction $Y$

\section{Figure 3}

Variation of the $\gamma / \gamma_{z}$ ratio along the building height in both directions for beams

minimum and maximum) were calculated for the variable involved in the study, the $\gamma / \gamma_{z}$ ratio. The results obtained are shown in table [5]. The histograms presented in figures [4] and [5], respectively corresponding to columns and beams, were made to provide a graphic view of the $\gamma / \gamma_{z}$ variable.

In table [5] it can be observed that the $\gamma / \gamma_{z}$ ratio ranges from 0.77 (or 0.78 ) to 1.14 , with a mean lower than 1.0 , both for columns and beams. It is shown that approximately $50 \%$ of the $\gamma / \gamma_{z}$ values are lower than 0.990 for columns and 0.970 for beams. Additionally, the $\gamma / \gamma_{z}$ variability may be considered small since the coefficients of variation obtained range from $6 \%$ to $7 \%$. It is important to note that the coefficient of variation is a measure that expresses variability in relative terms, comparing the standard deviation with the mean,

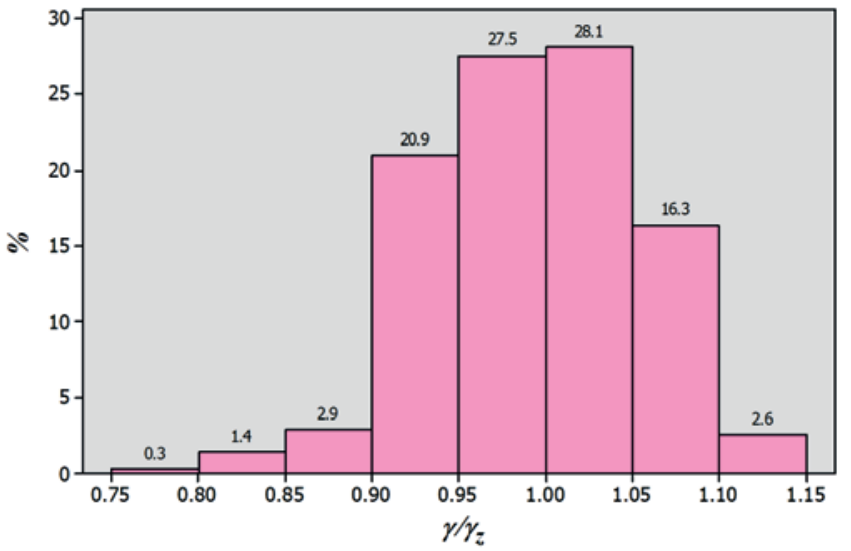

Figure 4

Histogram for the $\gamma / \gamma_{z}$ variable correspondent to columns

and may be considered small when it is not above $30 \%$.

In observing the histograms in figures [4] and [5], it can be seen that the $\gamma / \gamma_{z}$ values are lower than 1.05 in $81 \%$ of the cases for columns and in $87 \%$ for beams. This means that for the most part of the situations, magnifying first order moments by $\gamma_{z}$ would provide a maximum error opposing to safety lower than $5 \%$. It can also be noted that, in the case of columns, frequencies are greater for $\gamma /$ $\gamma_{z}$ values ranging from 0.95 to 1.05 . As to beams, the frequency is higher within a $0.95 \leq \gamma / \gamma_{z}<1.00$ interval. Also of note is the fact that only approximately $7 \%$ of the $\gamma / \gamma_{z}$ values for columns, and $12 \%$ for beams, are out of a $0.90 \leq \gamma / \gamma_{z}<1.10$ interval.

The Kruskal-Wallis test was adopted to assess whether the $\gamma / \gamma_{z}$ ratio varies significantly in accordance with the building, or whether the results obtained for different buildings could be similar. Table [6] presents the results for both columns and beams. Statistics $H$ are observed to be higher than $\chi_{0,05,9}^{2}$ critical values and, then, the null hypothesis $H_{0}$ must be rejected in favor of alternative hypothesis $H_{1}$. Therefore, it is possible to conclude that there are significant differences in the value obtained for the $\gamma / \gamma_{z}$ ratio, both

\section{Table 5}

Basic descriptive measurements for $\gamma / \gamma_{z}$ variable

\begin{tabular}{|c|c|c|c|c|c|c|c|}
\hline Variable & $\begin{array}{c}\text { Sample size } \\
(n)\end{array}$ & Mean & $\begin{array}{c}\text { Standard } \\
\text { deviation }\end{array}$ & $\begin{array}{c}\text { Coefficient } \\
\text { of variation } \\
(\%)\end{array}$ & Minimum & Median & Maximum \\
\hline$\gamma / \gamma_{z}$ columns & 349 & 0.988 & 0.060 & 6.120 & 0.780 & 0.990 & 1.140 \\
\hline$\gamma / \gamma_{z}$ beams & 349 & 0.975 & 0.065 & 6.720 & 0.770 & 0.970 & 1.140 \\
\hline
\end{tabular}

\section{Table 6}

Results of Kruskal-Wallis test for columns and beams (verifying differences per buildings)

\begin{tabular}{|c|c|c|}
\hline Item & Columns & Beams \\
\hline $\mathbf{H}$ & 30.005 & $\mathbf{4 8 . 3 8 6}$ \\
\hline$\chi_{0,05,9}^{2}$ & 16.92 & $\mathbf{0 . 0 0 0}$ \\
\hline $\mathbf{p}$ & $\mathbf{0 . 0 0 0}$ & $\mathbf{0 . 0 5}$ \\
\hline$\alpha$ & $\mathbf{0 . 0 5}$ & $\mathbf{H}_{\mathbf{0}}$ rejected \\
\hline Conclusion & $\mathbf{H}_{0}$ rejected & \\
\hline
\end{tabular}




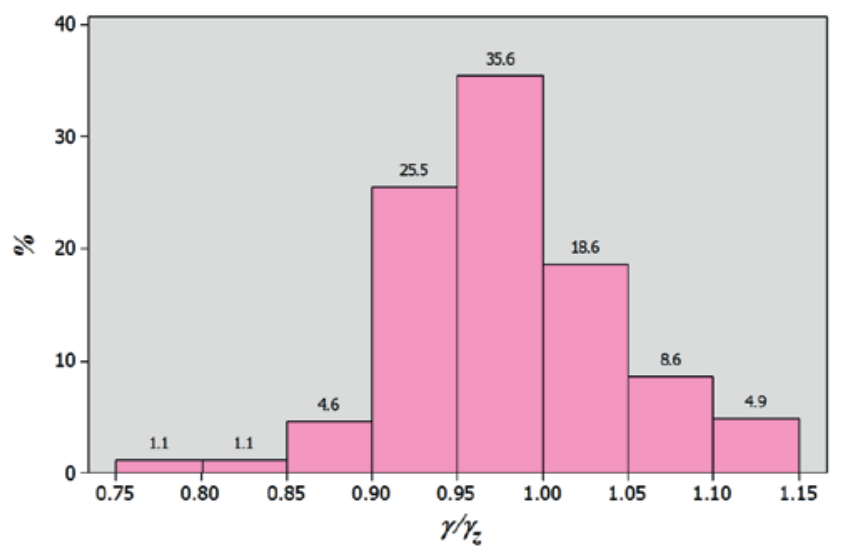

Figure 5

Histogram for the $\gamma / \gamma_{z}$ variable correspondent to beams

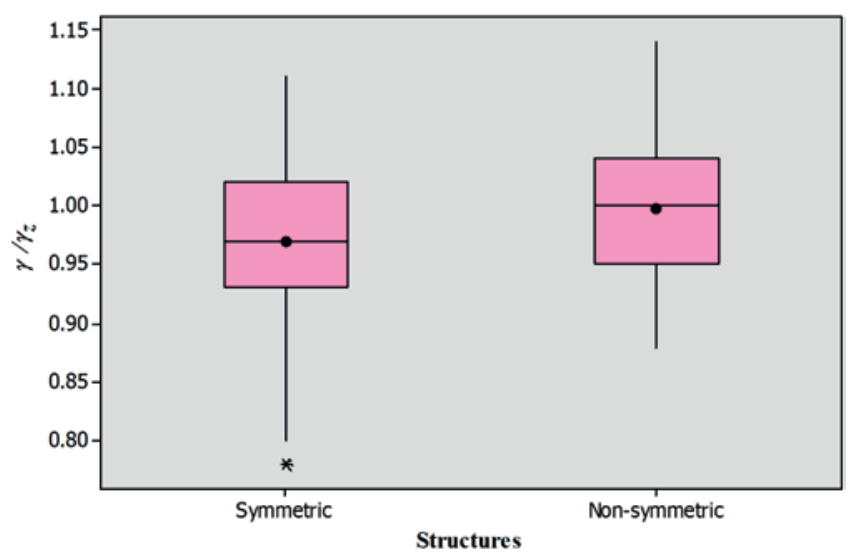

\section{Figure 6}

Boxplot for the $\gamma / \gamma_{z}$ variable stratified by structure symmetry, corresponding to columns

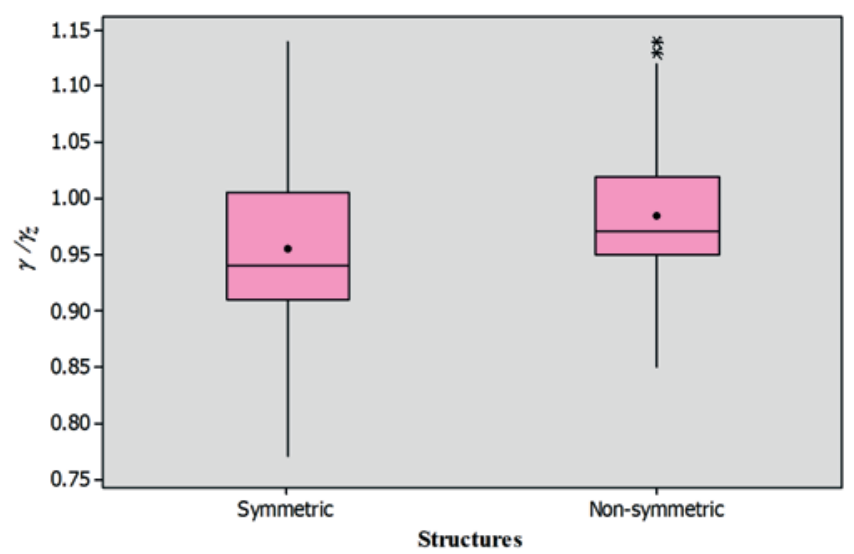

Figure 7

Boxplot for the $\gamma / \gamma_{z}$ variable stratified by structure symmetry, corresponding to beams for columns and beams, in accordance with the building being analyzed. The same conclusion can be made observing that $p$ is lower than the level of significance $\alpha=0.05$.

It is also interesting to study the distribution of $\gamma / \gamma_{z}$ taking in consideration a possible symmetry of the structure. So, the structures were divided into two groups: the group of "symmetric" structures (constituted by double symmetry buildings), and the group of "nonsymmetric" structures (remaining buildings). Boxplots shown in figures [6] and [7] were then constructed correspondingly to columns and beams, respectively. In these charts, the horizontal segment located inside the rectangle represents the median, the circle represents the mean, and the asterisks correspond to discrepant observations, named outliers.

In figure [6] boxplot, it can be noted that for columns the $\gamma / \gamma_{z}$ ratio ranges from 0.78 to 1.11 , in "symmetric" structures, and from 0.88 to 1.14 in "non-symmetric" structures. It can also be observed that "non-symmetric" structures feature greater mean and median than the "symmetric" ones, which, in turn, show results with greater variability. It is worth mentioning that in double symmetry buildings, $75 \%$ of the results were lower 1.02 ; this value increases to 1.04 in "non-symmetric" structures. The presence of an outlier for "symmetric" structures corresponding to $\gamma / \gamma_{z}=0.78$ is verified.

When analyzing figure [7] boxplot, regarding beams, it can be noted that the values obtained for the $\gamma / \gamma_{z}$ ratio are ranging from 0.77 to 1.14 for "symmetric" structures, and from 0.85 to 1.14 for the "non-symmetric" ones. As seen in the case of columns, "symmetric" structures present greater variability, though featuring mean and median lower than the "non-symmetric" ones. Additionally, in both groups of buildings at least $75 \%$ of the results are lower than 1.02. It is important to explain that "non-symmetric" structures presented two discrepant observations relative to $\gamma / \gamma_{z}$ values equal to 1.13 and 1.14 .

A Mann-Whitney test was made with the goal of verifying if there are statistical evidences that "symmetric" structures are different from "non-symmetric" structures, in relation to the $\gamma / \gamma_{z}$ value obtained. The results for columns and beams are shown in table [7]. In this table, by comparing $\left|z_{0}\right|$ and $z_{0,025}$ (or between $p$ and $\alpha$ ), it was verified that null hypothesis $H_{0}$ must be rejected in both cases. Consequently, it can be said that there are relevant differences in variable $\gamma / \gamma_{z}$ in function of the structure considered ("symmetric" or "non-symmetric"), i.e. the existence or non-existence of symmetry significantly influences the $\gamma / \gamma_{z}$ value.

\section{Final considerations}

In this study, a simplified process of final moments assessment using $\gamma_{z}$ coefficient as magnifier for first order moments was analyzed taking in consideration the variation of second order effects along building heights. For the analysis, a $\gamma / \gamma_{z}$ ratio was determined, with " $\gamma$ " being denominated first order moments magnifier (relation between moments obtained by analysis in second and first order for columns and beams along the height of buildings).

It was observed that the $\gamma / \gamma_{z}$ ratio ranged from 0.77 (or 0.78 ) to 1.14 (means and medians obtained lower than 1.0), and that nearly $90 \%$ of all values were found to be within the $0.90 \leq \gamma / \gamma_{z}<1.10$ interval, for both columns and beams. Additionally, in $81 \%$ of the cases for columns, and in $87 \%$ for beams, the $\gamma / \gamma_{z}$ ratio was lower 
Table 7

Results of Mann-Whitney test for columns and beams (verifying differences per "symmetric" x "non-symmetric" structures)

\begin{tabular}{|c|c|c|}
\hline Item & Columns & Beams \\
\hline$\left|z_{0}\right|$ & 3.690 & 4.817 \\
\hline$z_{0,025}$ & 1.96 & 1.96 \\
\hline $\mathrm{p}$ & 0.000 & 0.000 \\
\hline$\alpha$ & 0.05 & 0.05 \\
\hline Conclusion & $\mathrm{H}_{0}$ rejected & $\mathrm{H}_{0}$ rejected \\
\hline
\end{tabular}

than 1.05 , indicating that, in most cases, magnifying first order moments by $\gamma_{z}$ would provide a maximum error lower than $5 \%$ opposing to safety.

Hypothesis tests (Kruskal-Wallis and Mann-Whitney) were made to assess if the $\gamma / \gamma_{z}$ ratio varies significantly in accordance with the building and the type of structure ("symmetric" and "non-symmetric"). However, it is important to note that the hypothesis tests show whether the groups differ or not from a statistical point of view, that is, whether the differences obtained between samples are or are not "statistically significant". Then, the right interpretation of the results of the tests must be made by the researcher based on previous knowledge and observing if the "statistical significance" in fact represents a "practical significance", or as defined by Montgomery \& Runger [19], an "engineering significance". Based on these considerations and on the statistic study conducted, it can be stated that:

- there are significant differences in the value obtained for the $\gamma /$ $\gamma_{z}$ ratio in accordance with the building analyzed, both for columns and for beams. This result is reasonable, as the safety related to the simplified method of assessment of final moments using the $\gamma_{z}$ coefficient will be greater in "well-behaved" buildings (i.e., those that do not feature very discrepant ceiling heights or abrupt changes of inertia between stories, for example), for which the hypothesis formulated in the development of the method (that successive displacements form a geometric progression) is indeed valid. Hence, in these cases, the $\gamma / \gamma_{z}$ ratio shall be smaller or equal to 1 . On the other hand, for "less well-behaved" buildings, the hypothesis adopted is applicable with greater errors, consequently, the real magnifier $\gamma$ tends to be greater than the $\gamma_{z}$ value calculated, as explained by Vasconcelos [22];

- "symmetric" structures proved to be different from "non-symmetric" structures in regard to the $\gamma / \gamma_{z}$ value obtained, both for columns and for beams. Additionally, for "non-symmetric" structures, mean and median values of the $\gamma / \gamma_{z}$ variable were found to be greater than those from "symmetric" structures. These are predictable facts, since the presence or the lack of symmetry influences behavior of structures and, consequently, the $\gamma / \gamma_{z}$ value, as explained before, tends to be smaller for symmetric "well-behaved" buildings. In brief, the conclusion that the $\gamma / \gamma_{z}$ ratio varies significantly in accordance with the building and with the type of structure ("symmetric" or "non-symmetric") is coherent, indicating that safety related to the simplified process of assessing final moments using $\gamma_{z}$ coefficient is not the same for all cases, but it depends on specific characteristics of the buildings that promote greater or smaller proximity to the hypothesis formulated during the development of the method.

Therefore, it is here suggested for new researches, the study of the $\gamma_{z}$ coefficient efficiency as a magnifier of first order moments in structures that present irregularities in geometry, as for instance, changes in inertia and ceiling heights between stories.

\section{Bibliographical references}

[1] ASSOCIAÇÃO BRASILEIRA DE NORMAS TÉCNICAS. NBR 6118 - Projeto de estruturas de concreto - Procedimento. Rio de Janeiro, versão corrigida, 2014.

[2] CARMO, R.M.S. Efeitos de segunda ordem em edifícios usuais de concreto armado. São Carlos. Dissertação (Mestrado) - Escola de Engenharia de São Carlos, Universidade de São Paulo, 1995.

[3] LIMA, J.S.; GUARDA, M.C.C. Comparação entre o parâmetro alfa e o coeficiente $\gamma_{z}$ na análise da estabilidade global de edifícios altos. In: CONGRESSO BRASILEIRO DO CONCRETO, 41., Salvador. Anais, 1999.

[4] OLIVEIRA, D.M. Parâmetros de instabilidade global das estruturas de concreto armado segundo a nova NBR-6118. Belo Horizonte. Dissertação (Mestrado) - Escola de Engenharia da Universidade Federal de Minas Gerais, 2002.

[5] OLIVEIRA, D.M.; SILVA, N.A.; OLIVEIRA, P.M.; RIBEIRO, C.C. Evaluation of second order moments in reinforced concrete structures using the $\gamma_{z}$ and $B_{2}$ coefficients. Revista Ibracon de Estruturas e Materiais, v. 7, n. 3, p. 329-348, jun. 2014.

[6] ANSYS Inc. Ansys Release 9.0 - Theory Reference, 2004.

[7] FRANCO, M.; VASCONCELOS, A.C. Practical assessment of second order effects in tall buildings. In: COLOQUIUM ON THE CEB-FIP MC90, Rio de Janeiro. Proceedings, p.307323, 1991.

[8] FRANÇA, R.L.S. São Paulo, 23 out 2012. Entrevista concedida a Mônica Maria Emerenciano Bueno apud BUENO, M.M.E. Estudo de valores aproximados de rigidez equivalente para vigas e pilares para análises não-lineares globais em estruturas de concreto armado de pequeno porte. Brasília. Tese (Doutorado) - Faculdade de Tecnologia da Univer- 
sidade de Brasília, 2014.

[9] BUENO, M.M.E. Estudo de valores aproximados de rigidez equivalente para vigas e pilares para análises não-lineares globais em estruturas de concreto armado de pequeno porte. Brasília. Tese (Doutorado) - Faculdade de Tecnologia da Universidade de Brasília, 2014.

[10] LACERDA, M.M.S.; FLORÊNCIO, A.C.; SILVA, W.A.; DELALIBERA, R.G. Avaliação dos critérios para análise da estabilidade global em edifícios de concreto armado: estudo de caso. Revista Eletrônica de Engenharia Civil, v. 9, n. 2, p. 24-37, out. 2014.

[11] FREITAS, F.C. Avaliação da estabilidade global de edifícios com e sem elementos de contraventamento. Vitória. Dissertação (Mestrado) - Centro Tecnológico da Universidade Federal do Espírito Santo, 2015.

[12] FREITAS, F.C.; LUCHI, L.A.R; FERREIRA, W.G. Global stability analysis of structures and actions to control their effects. Revista Ibracon de Estruturas e Materiais, v. 9, n. 2, p. 192-213, abr. 2016.

[13] PASSOS, V.M.; FEITOSA, L.A; ALVES, E.C.; AZEVEDO, M.S. Analysis of instability of tall buildings with prestressed and waffle slabs. Revista Ibracon de Estruturas e Materiais, v. 9, n. 2, p. 244-262, abr. 2016.

[14] FEITOSA, L.A; ALVES, E.C. Study of global stability of tall buildings with prestressed slabs. Revista Ibracon de Estruturas e Materiais, v. 8, n. 2, p. 196-224, abr. 2015.

[15] ASSOCIAÇÃO BRASILEIRA DE NORMAS TÉCNICAS. Projeto de revisão da NBR 6118 - Projeto de estruturas de concreto. Rio de Janeiro, 2000.

[16] MONCAYO, W.J.Z. Análise de segunda ordem global em edifícios com estrutura de concreto armado. São Carlos. Dissertação (Mestrado) - Escola de Engenharia de São Carlos da Universidade de São Paulo, 2011.

[17] LEVIN, J.; FOX; J.A.; FORDE, D.R. Estatística para ciências humanas. 11.ed. São Paulo: Pearson Education do Brasil, 2012.

[18] WERKEMA, M.C.C.; AGUIAR, S. Otimização estatística de processos: como determinar a condição de operação de um processo que leva ao alcance de uma meta de melhoria. Belo Horizonte, Fundação Christiano Ottoni, Escola de Engenharia da Universidade Federal de Minas Gerais (Série Ferramentas da Qualidade, vol.9), 1996.

[19] MONTGOMERY, D.C.; RUNGER; G.C. Estatística aplicada e probabilidade para engenheiros. Rio de Janeiro, Livros Técnicos e Científicos, 2003.

[20] WERKEMA, M.C.C.; DRUMOND, F.B.; AGUIAR, S. Análise de variância: comparação de várias situações. Belo Horizonte, Fundação Christiano Ottoni, Escola de Engenharia da Universidade Federal de Minas Gerais (Série Ferramentas da Qualidade, vol.6), 1996.

[21] MINITAB Inc. Minitab Statistical Software, Release 14 for Windows, 2003.

[22] VASCONCELOS, A.C. Em que casos não se deve aplicar o processo simplificado do $\gamma_{z}$ para determinação dos efeitos de $2^{\mathrm{a}}$ ordem?. In: SIMPÓSIO DE ATUALIZAÇÃO SOBRE A NOVA NB-1, Belo Horizonte, 2002. 